\title{
Sodium Oxybate in the Treatment of Binge Eating Disorder: An Open-Label, Prospective Study
}

\author{
Susan L. McElroy, MD ${ }^{1,2}$ \\ Anna I. Guerdjikova, PhD, \\ MSW $^{1,2 *}$ \\ Erin L. Winstanley, PhD ${ }^{1,2}$ \\ Anne M. 0'Melia, MD ${ }^{1}$ \\ Nicole Mori, CNP ${ }^{1,2}$ \\ Paul E. Keck Jr., MD ${ }^{1,2}$ \\ James I. Hudson, MD, ScD ${ }^{3}$
}

\begin{abstract}
Objective: To assess preliminarily the effectiveness of sodium oxybate in binge eating disorder.

Method: This was an open-label, prospective, 16-week, flexible dose study of sodium oxybate in binge eating disorder. The primary outcome was binge eating episode frequency.
\end{abstract}

Results: Twelve individuals received sodium oxybate, 10 completed at least one postbaseline evaluation, and five completed the study. Mean dose at endpoint was 7.1 (2.0) g/day. Sodium oxybate was associated with significant reductions in frequency of binge days and binge episodes, as well as measures of clinical se- verity, eating pathology, obsessive-compulsive symptoms, food cravings, body mass index, and body weight. Nine participants had remission of binge eating and five lost $\geq 5 \%$ of their baseline weight; all five of the latter participants had remission of binge eating.

Discussion: In this open-label trial, sodium oxybate was effective in binge eating disorder, but associated with high a discontinuation rate. (C) 2010 by Wiley Periodicals, Inc.

Keywords: binge eating disorder; pharmacotherapy; sodium oxybate

(Int J Eat Disord 2010; 00:000-000)

\section{Introduction}

Binge eating disorder is characterized by recurrent, distressing episodes of binge eating without the inappropriate compensatory weight loss behaviors of bulimia nervosa. ${ }^{1}$ It has a lifetime prevalence of about $2-3 \%$, is often chronic, and is associated with psychopathology (mood, anxiety, and substance use disorders), obesity, reduced quality of life, and disability. $^{2-4}$

Despite growing awareness of the significance of binge eating disorder as a public health problem, it has no pharmacological treatment approved by the Food and Drug Administration (FDA). ${ }^{5}$ Several psychological interventions and selective serotonin reuptake inhibitors (SSRIs) reduce binge eating, but not all patients respond adequately. ${ }^{6,7}$ In addition, these treatments are generally ineffective for

\footnotetext{
Accepted 20 November 2009

Supported by Jazz Pharmaceuticals.

*Correspondence to: Anna I. Guerdjikova, PhD, MSW, Lindner Center of HOPE and Department of Psychiatry, University of Cincinnati College of Medicine, 4075 Old Western Row Road Mason,

Ohio 45040. E-mail: anna.guerdjikova@lindnercenter.org

${ }^{1}$ Research Institute, Lindner Center of HOPE, Mason, Ohio

${ }^{2}$ Department of Psychiatry, University of Cincinnati College of Medicine, Cincinnati, Ohio

${ }^{3}$ Department of Psychiatry, Harvard Medical School and Biological Psychiatry Laboratory, McLean Hospital, Belmont, Massachusetts

Published online in Wiley InterScience

(www.interscience.wiley.com). DOI: 10.1002/eat.20798

() 2010 Wiley Periodicals, Inc.
}

the associated obesity. The antiepileptics topiramate and zonisamide ${ }^{8-10}$ the selective norepinephrine reuptake inhibitor atomoxetine, ${ }^{11}$ and the selective serotonin norepinephrine reuptake inhibitor (SNRI) sibutramine ${ }^{12,13}$ have been shown to decrease both binge eating and excessive body weight, but are associated with problematic adverse events and/or low levels of persistent use. ${ }^{5,14,15}$ Novel treatments that reduce both binge eating and body weight and that are well tolerated are therefore needed for binge eating disorder.

Gamma-hydroxybutyrate (GHB) is a unique compound that is an endogenous molecule [a short-chain fatty acid synthesized within the central nervous system (CNS)], a drug of abuse (illicit GHB), and a therapeutic drug marketed for the treatment of excessive daytime sleepiness and cataplexy in patients with narcolepsy (sodium oxybate; Xyrem $\left.{ }^{\circledR}\right) \cdot{ }^{16-18}$ Sodium oxybate is also currently being evaluated as a treatment for fibromyalgia, and preliminary trials indicate efficacy and good tolerability for this indication. ${ }^{19,20}$ Because of GHB's association with abuse and severe central nervous system (CNS) depressant effects, including respiratory depression, coma, and death when taken in overdose, ${ }^{21-23}$ sodium oxybate was approved by the FDA as a Schedule III drug with a black box warning stating it is a "central nervous system depressant with abuse potential" that "should not be used with alcohol or other CNS depressants." $^{24}$ It is presently available only 
through a centralized pharmacy, the Xyrem Success Program, ${ }^{25}$ which provides educational materials to both prescriber and patient explaining the risks and proper use of sodium oxybate, along with the required prescription form. Preliminary experience with the Success Program has found very little abuse of sodium oxybate when prescribed in this manner. ${ }^{22,25}$

Several lines of evidence suggested that sodium oxybate might be a useful treatment for binge eating disorder. First, present in human brain as a metabolite of gaba-aminobutyric acid (GABA), and with at least two identified receptors, GHB modulates a number of neurotransmitters involved in the regulation of feeding behavior, including GABA, dopamine, serotonin, opioids, and glutamate. ${ }^{17}$ Thus, chronic GHB administration has been shown to decrease food-maintained behavior in baboons, ${ }^{26}$ and the GHB analogue GET73 has been shown to reduce preference for palatable food in rats. ${ }^{27} \mathrm{Sec}$ ond, sodium oxybate treatment has been associated with weight loss in patients with narcolepsy. ${ }^{28}$ Most agents associated with weight loss studied thus far in binge eating disorder have been shown effective for both binge eating and body weight reduction. ${ }^{15}$ Moreover, growing research has suggested that binge eating disorder and narcolepsy may be pathophysiologically related. Like binge eating disorder, narcolepsy co-occurs with obesity, ${ }^{29-32}$ and conversely disturbed eating behaviors, including binge eating, ${ }^{32-35}$ co-occurs with narcolepsy. For example, in a case control study, $23 \%$ of 60 patients with narcolepsy and cataplexy met criteria for a clinical eating disorder as opposed to none of 120 healthy controls. ${ }^{35}$ The majority of patients experienced eating disorder symptoms, with an irresistible craving for food and binge eating being the most prominent features. Indeed, it has been hypothesized that binge eating may mediate the relationship between narcolepsy and obesity. ${ }^{34}$

A third line of evidence suggesting sodium oxybate may be a useful treatment for binge eating disorder is that GHB has been shown effective in suppressing craving for alcohol and reducing alcohol consumption in patients with alcohol use disorders in randomized, controlled trials. ${ }^{36-40}$ Preclinical, phenomenologic, and comorbidity data suggest binge eating disorder and substance use disorders are related ${ }^{2,41,42}$ and growing research shows that medications that reduce craving and consumption of drugs of abuse ${ }^{43}$ may also reduce binge eating., ${ }^{8,15,44,45}$ Indeed, one such drug, baclofen, shares a common mechanism with sodium oxybate-agonism of centrally active GABA-B receptors. ${ }^{45}$
Finally, sodium oxybate is well tolerated when taken as prescribed. ${ }^{16,17,24}$ Compared with the antidepressants, antiepileptics, and antiobesity agents presently used in binge eating disorder, sodium oxybate is associated with lower rates of sexual dysfunction, cognitive impairment, and hypertension, respectively.

Because of these observations, we conducted an open-label trial of sodium oxybate in 12 patients with binge eating disorder.

\section{Method}

\section{Study Design}

This was an open-label, 22-week, prospective, flexibledose, single-center study conducted at the University of Cincinnati Medical Center and the Lindner Center of HOPE. After a 1-4 week screening period, qualified participants entered a 16-week treatment period during which they received open-label sodium oxybate. Sodium oxybate was discontinued at the last visit of the treatment period. This visit was followed by a 2 -week post-treatment assessment period.

During the treatment period, study visits were conducted weekly for the first 6 weeks and then every 2 weeks for the remaining 10 weeks. Sodium oxybate was dispensed in $180 \mathrm{~mL}$ bottles containing $500 \mathrm{mg} / \mathrm{mL}$ sodium oxybate. Participants were instructed to take $4.5 \mathrm{~g} / \mathrm{night}$, divided into two equal doses of $2.25 \mathrm{~g}$, for the first 2 weeks, following which the dose could be increased by $1.5 \mathrm{~g} /$ night every 2 weeks as tolerated to a maximum dose of $9 \mathrm{~g} /$ night. The minimum dose allowed was $3.0 \mathrm{~g} /$ night. In the last 4 weeks of the treatment period, the dosage was not altered unless side effects required a dosage reduction.

\section{Participant Selection Criteria}

Study participants were individuals recruited from advertisements for a medication trial for persons with binge eating. They were eligible for the study if they met DSM-IV-TR criteria for binge eating disorder ${ }^{1}$; had a body mass index (BMI) $\geq 18 \mathrm{~kg} / \mathrm{m}^{2}$ or $\leq 40 \mathrm{~kg} / \mathrm{m}^{2}$; and were 21 through 65 years of age. Participants were excluded if they met any of the following criteria: (1) had a lifetime history of a DSM-IV-TR diagnosis of a substance abuse or dependence disorder, except for nicotine or caffeine abuse or dependence (as determined by psychiatric history, Structured Clinical Interview for DSMIV-TR, ${ }^{46}$ and urine toxicology); (2) had a history of a personality disorder (e.g., schizotypal, borderline, or antisocial) which might interfere with assessment or compliance with study procedures; (3) were displaying current clinically significant depressive symptoms, defined as a 
major depressive episode by DSM-IV-TR criteria or a Montgomery Asberg depression rating scale (MADRS) ${ }^{47}$ score $>24$; (4) had clinically significant suicidality or homicidality, had made $\geq 1$ lifetime suicide attempts, or had a MADRS suicide item score $\geq 2$; (5) had a lifetime history of a DSM-IV-TR psychotic disorder, bipolar disorder, or dementia; (6) had a clinically unstable medical illness; (7) had obstructive sleep apnea (OBS) or received a high risk score for OBS on the Berlin Questionnaire ${ }^{48}$; (8) required treatment with any drug that might interact adversely with or obscure the action of the study medication (e.g., stimulants, CNS depressants, antidepressants, or antiobesity agents); (9) were receiving formal psychotherapy for binge eating disorder which was begun within 3 months before the baseline visit; (10) had received any psychoactive medication within 1 week before the baseline visit; (11) had previously been treated with sodium oxybate or had received an experimental drug or used an experimental device in the past 30 days; or (12) had $<2$ binge days in the week before their baseline visit. All patients were biochemically euthyroid prior baseline. Women were excluded if they were pregnant, lactating, or if fertile, not practicing a medically accepted form of contraception.

\section{Participant Evaluation}

The Institutional Review Board at the University of Cincinnati Medical Center approved the study protocol. All participants provided written informed consent before administration of any study procedures and were enrolled from December 5, 2007 through December 17, 2008.

All participants underwent a screening evaluation that included an interview for demographic information and medical and psychiatric histories; the Structured Clinical Interview for DSM-IV-TR (SCID-I/P) ${ }^{49}$ to establish the diagnosis of binge eating disorder and determine comorbid Axis I diagnoses; the eating disorder examination (EDE) ${ }^{50}$ to confirm the diagnosis of binge eating disorder; the MADRS to assess for depressive symptoms and suicidality; the Berlin Questionnaire ${ }^{48}$ to identify those at high risk for OBS; a physical examination; vital signs; height and weight measurements to determine BMI; waist circumference; electrocardiogram (ECG); urine pregnancy and toxicology tests; and blood chemical and hematological tests. At the screening evaluation and each of the following visits, participants were given take-home diaries in which they recorded binge eating episodes (number of episodes per day, types of food consumed, and duration of the episodes).

\section{Outcome Measures}

The primary outcome measure was the weekly frequency of binge eating episodes (binge frequency), defined as the mean number of binges per week in the interval between visits (total number of binges in the interval, divided by number of days in the interval, and multiplied by 7). Binge episodes were defined using DSM-IV-TR criteria ${ }^{1}$ and assessed via clinical interview and review of take-home diaries.

Secondary outcome measures were weekly frequency of binge days (days during which there were one or more binges); body weight (kg); BMI (body weight in $\mathrm{kg}$ divided by height in $\mathrm{m}^{2}$ ); and scores on the clinical global impressions severity (CGI-S) and clinical global impressions improvement (CGI-I) ${ }^{51}$ scales; Yale Brown obsessive compulsive scale-modified for binge eating (YBOCS$\mathrm{BE})^{52}$; Three factor eating questionnaire (TFEQ $)^{53}$; MADRS; and food craving inventory (FCI) ${ }^{54}$ All measures were obtained at every visit except the TFEQ and FCI, which were obtained every 4 weeks. Other secondary outcome measures included the percentage of participants who achieved remission of binge eating, defined as no binge eating episodes for 1 month (including only nonmissing consecutive observations); the percentage of participants who lost $\geq 5 \%$ of their baseline weight (difference between baseline and endpoint); and the percentage of participants who had remission of binge eating for 1 month and lost $\geq 5 \%$ of baseline body weight.

Assessed safety measures included adverse events, physical examination findings, clinical laboratory data, and vital signs. Adverse events were obtained through spontaneous patient reporting and by open-ended investigator questioning. Reportable adverse events were new symptoms or illnesses that occurred during the treatment phase and those that increased in severity compared with baseline. A urine toxicology test was performed every 4 weeks.

\section{Statistical Analysis}

The primary analysis for each outcome that was assessed at every visit (frequency of binges, frequency of binge days, BMI, weight, CGI-S, and YBOCS-BE) was a longitudinal repeated-measures random regression analysis similar to that we have used in previous open-label studies of binge eating disorder. ${ }^{55,56}$ The longitudinal analysis assessed the rate of change of each outcome variable measured at each visit during the treatment period (binge episodes, binge days, weight, BMI, CGI-S, YBOCS-BE, and MADRS). We used a model for the mean of the outcome variable that included a term for time. We modeled time as a continuous variable, with weeks ranging from 0 at baseline to 16 at the week 16 visit after beginning treatment with sodium oxylate. The measure of effect was the estimated change in the outcome at week 16. For the analysis of binge day frequency and binge frequency, we used the logarithmic transformation log ([binges/week] +1 ) to normalize the data and stabilize variance. For all outcome variables except for weight and BMI, we used a square root transformation for time, 
TABLE 1. Clinical characteristics and measures, by participant

\begin{tabular}{|c|c|c|c|c|c|c|c|c|c|}
\hline Pt No & $\begin{array}{l}\text { Age/Duration of } \\
\text { Illness (years) }\end{array}$ & Race & $\begin{array}{c}\text { Baseline Weekly } \\
\text { Binge Eating } \\
\text { Episodes } \\
\text { Frequency }\end{array}$ & $\begin{array}{l}\text { Baseline } \\
\text { Weight } \\
(\mathrm{kg}) / \mathrm{BMI}\end{array}$ & $\begin{array}{c}\text { Weeks } \\
\text { of Trial } \\
\text { Completed }\end{array}$ & $\begin{array}{l}\text { Study End Weekly } \\
\text { Binge Eating } \\
\text { Episodes } \\
\text { Frequency }\end{array}$ & $\begin{array}{l}\text { Study End } \\
\text { Weight } \\
\text { (kg)/BMI }\end{array}$ & $\begin{array}{l}\text { Change in } \\
\text { Weight (kg) }\end{array}$ & $\begin{array}{l}\text { Remission } \\
\text { Duration } \\
\text { (in weeks) }\end{array}$ \\
\hline 1 & $53 / 39$ & W & 3 & $103.9 / 36.6$ & 14 & 0 & $97.9 / 34.5$ & -6.0 & 14 \\
\hline 2 & $56 / 16$ & W & 2.3 & $74.8 / 30.2$ & 6 & 4.6 & $74.8 / 30.2$ & 0.0 & $\mathrm{n} / \mathrm{a}$ \\
\hline 3 & $47 / 41$ & W & 4 & $95.9 / 35.2$ & 16 & 0 & 86/31.6 & -9.9 & 11 \\
\hline 4 & $44 / 15$ & $B$ & 7 & $103.1 / 34.6$ & 5 & 0 & $102.2 / 34.3$ & -0.9 & 4 \\
\hline 5 & $40 / 30$ & W & 4 & $98.5 / 32.9$ & 16 & 0 & $90.1 / 30.1$ & -8.4 & 6 \\
\hline 6 & $33 / 5$ & W & 4 & $91.6 / 33.6$ & 16 & 0 & $88 / 32.3$ & -3.6 & 4 \\
\hline 7 & $36 / 10$ & $B$ & 3.5 & $88.5 / 30.6$ & 14 & 0 & $82.4 / 28.5$ & -6.1 & 6 \\
\hline 8 & $58 / 32$ & W & 12 & 81.8/31.6 & 5 & 0 & 82/31.6 & +0.2 & $\mathrm{n} / \mathrm{a}$ \\
\hline 9 & $32 / 4$ & W & 7.9 & $100.9 / 37.9$ & 16 & 0 & 101/38 & +0.1 & 4 \\
\hline 10 & $52 / 44$ & W & 4 & $94.2 / 35$ & 16 & 0 & $85.5 / 31.8$ & -8.7 & 8 \\
\hline
\end{tabular}

Notes: All participants were women (W, White; B, Black), only 1 participant (\#1) had lifetime psychiatric diagnoses (history of a single major depressive episode, onset at age 27 , and history of panic disorder, onset at age 27 ). BMI, body mass index (weight in kilograms divided by height in $\mathrm{m}^{2}$.

because the response of these measures was approximately linear on the square root scale. To account for the correlation of observations within individual's analysis, we used PROC MIXED in SAS software (version 9.1, Cary, N.C.) to calculate the standard errors of the parameter estimates using the best-fitting of the following covariance structures: first-order antidependence, heterogeneous autoregressive, and autoregressive. The longitudinal analysis is intent-to-treat, using available observations on all participants who completed a baseline evaluation.

The primary analysis for all other outcome measures, and a secondary analysis of the outcomes assessed at every visit, was an endpoint analysis of the change from baseline, applying a one-sample t test to the last observation carried forward (LOCF) with the null hypothesis being no change from baseline. We performed this analysis using Stata software (version 10.2, College Station, TX).

We set alpha at 0.05 , two-tailed, for statistical significance.

\section{Results}

Of 17 individuals screened, five were not enrolled because they: were considered high risk for sleep apnea $(N=2)$, withdrew consent $(N=2)$; or were lost-to-follow up $(N=1)$. Twelve individuals met entry criteria and received sodium oxybate (sample used for safety analysis). All 12 were women, their mean age at baseline was 45.1 years ( $S D=9.6)$, seven were White, five were Black, and the mean age of onset of binge eating disorder onset was 21.5 years $(\mathrm{SD}=11.2$, range $6-40$ years). The intention to treat (ITT) sample included all participants $(N=$ 10) with at least one post-baseline outcome measure (Table 1). Five participants completed the 16week trial; the other 5 discontinued prematurely, after a mean of 65.6 (SD = 35.9) days in the study, for the following reasons: lack of effectiveness $(N=$
$1)$, adverse events $(N=1)$, dosing inconvenience $(N=1)$, and lost to follow-up $(N=2)$. The adverse events leading to sodium oxybate discontinuation were chest pains, insomnia, and racing thoughts in one patient and headache and paresthesias in the other.

The mean (SD) daily dose at endpoint evaluation for all 10 participants was 7.1 (2.0) g. For the five study completers it was 7.8 (1.3) g.

The observed mean values for the outcome measures at last observation (for the 10 participants who had at least one post baseline visit) and at week 16 (for the five completers), along with the analysis of change in outcome measures, are presented in Table 2. The mean frequency of weekly binge eating episodes (see Fig. 1) and mean body weight (see Fig. 2) decreased steadily between baseline and endpoint. Both the longitudinal and endpoint analyses found a statistically significant decrease in frequency of binge eating episodes, frequency of binge eating days, weight, BMI, CGI-S and YBOCS-BE (total, obsession, and compulsion) scores (Table 2). The endpoint analysis yielded statistically significant reductions in TFEQ (cognitive restraint, inhibition, and hunger) and FCI scores (Table 2). MADRS scores, which were low at baseline as required by protocol, were not significantly decreased in either analysis (Table 2).

Eight participants had remission of binge eating at study termination, and five participants lost 5\% or more of their baseline weight at endpoint. The latter five participants also had remission of binge eating. There was not a statistically significant correlation between the change in weight and either binge episode frequency or binge day frequency.

The most common adverse effects reported by participants were: somnolence $(N=5)$, difficulty falling asleep or staying asleep $(N=4)$, vivid dreams $(N=3)$, anxiety $(N=2)$, nausea $(N=2)$, 
TABLE 2. Outcome measures before and after 16 weeks of treatment with sodium oxybate and analysis of change in outcome

\begin{tabular}{|c|c|c|c|c|c|c|c|c|}
\hline \multirow[b]{3}{*}{ Outcome Measure } & \multirow{2}{*}{\multicolumn{3}{|c|}{ Mean }} & \multicolumn{5}{|c|}{ Change from Baseline to Week 16} \\
\hline & & & & \multicolumn{2}{|c|}{ Longitudinal Analysis $^{\mathrm{a}}$} & \multicolumn{3}{|c|}{ Endpoint Analysis ${ }^{c}$} \\
\hline & $\begin{array}{l}\text { Baseline } \\
(N=10)\end{array}$ & $\begin{array}{c}\text { Last } \\
\text { Observation } \\
(N=10)^{\mathrm{b}}\end{array}$ & $\begin{array}{l}\text { Week } 16 \\
(N=5)^{c}\end{array}$ & $\begin{array}{l}\text { Estimate } \\
{[95 \% \mathrm{Cl}]}\end{array}$ & $p$ Value & & $\begin{array}{l}\text { Estimate } \\
{[95 \% \mathrm{Cl}]}\end{array}$ & $p$ Value \\
\hline Binges/wk & $5.2(3.0)$ & $0.5(1.5)$ & $0(0)$ & $-5.0[-8.6,-2.8]$ & $<0.001$ & -4.7 & {$[-7.4,-2.0]$} & $<0.001$ \\
\hline Binge days/wk & $4.4(1.6)$ & $0.5(1.5)$ & $0(0)$ & $-4.5[-7.6,-2.5]$ & $<0.001$ & -3.9 & {$[-5.8,-2.1]$} & $<0.001$ \\
\hline Weight (kg) & $93.3(9.4)$ & $89.0(8.9)$ & $90.1(6.3)$ & $-6.0[-8.3,-3.8]$ & $<0.001$ & -4.3 & {$[-7.2,-1.5]$} & 0.01 \\
\hline BMI $(\mathrm{kg} / \mathrm{m})$ & $33.8(2.5)$ & $32.3(2.7)$ & $32.8(3.1)$ & $-2.2[-3.0,-1.4]$ & $<0.001$ & -1.5 & {$[-2.6 .-0.5]$} & 0.01 \\
\hline CGI-S score & $4.8(0.8)$ & $1.6(1.1)$ & $1(0)$ & $-3.9[-4.7,-3.0]$ & $<0.001$ & -3.2 & {$[-4.3,-2.1]$} & $<0.001$ \\
\hline \multicolumn{9}{|l|}{ YBOCS-BE } \\
\hline Total & $21.6(2.7)$ & $5.9(5.1)$ & $4.2(2.7)$ & $-18.6[-22.9,-14.2]$ & $<0.001$ & -15.7 & {$[-19.9,-11.5]$} & $<0.001$ \\
\hline Obsessions & $10.2(1.8)$ & $3.5(2.6)$ & $2.8(1.6)$ & $-8.0[-10.3,-5.7]$ & $<0.001$ & -6.7 & {$[-9.3,-4.3]$} & $<0.001$ \\
\hline Compulsions & $11.4(1.3)$ & $2.4(2.9)$ & $1.4(1.1)$ & $-11.1[-12.3,-9.7]$ & $<0.001$ & -9.0 & {$[-11.2,-6.8]$} & $<0.001$ \\
\hline $\mathrm{FCl}$ score & $68.6(16.6)$ & $51.5(19.2)$ & $41.0(18.1)$ & & & -17.1 & {$[-30.4,-3.8]$} & 0.02 \\
\hline \multicolumn{9}{|l|}{ TFEQ score } \\
\hline Cognitive restraint & $5.1(3.7)$ & $9.0(3.2)$ & $11.3(1.5)$ & & & 3.9 & {$[0.9,6.9]$} & 0.02 \\
\hline Disinhibition & $13.8(1.9)$ & $8.8(4.6)$ & $9.3(5.7)$ & & & -5.0 & {$[-8.0,-2.0]$} & $<0.001$ \\
\hline Hunger & $11.7(0.7)$ & $7.5(1.9)$ & $9.0(9.2)$ & & & -4.2 & {$[-7.8,-0.6]$} & 0.03 \\
\hline MADRS score & $1.6(2.5)$ & $0.5(0.9)$ & $0.4(0.9)$ & $-0.9[-2.2,0.43]$ & 0.19 & -1.1 & {$[-2.6,0.4]$} & 0.13 \\
\hline
\end{tabular}

Notes: BMI, body mass index (weight in kilograms divided by height in $\mathrm{m}^{2}$ ); CGI-S, clinical global impression-severity; Cl, confidence interval; MADRS, Montgomery-Asberg depression rating scale; TFEQ, three-factor eating questionnaire; YBOCS-BE, Yale-Brown obsessive-compulsive scale modified for binge eating; FCl, Food Craving Inventory Scale.

${ }^{a}$ Only those outcomes assessed at each study visit were included in the longitudinal analyses.

bast Observation Endpoint was defined using last observation carried forward.

'Week 16 Endpoint was available for only those participants that completed the study.

edema $(N=2)$, flu-like symptoms $(N=2)$, and frequent urination $(N=2)$. There were no serious adverse events. There were no significant changes in laboratory tests. No participant reported or displayed symptoms of misuse or withdrawal.

\section{Discussion}

Open-label treatment with sodium oxybate in 10 individuals with binge eating disorder was associ-

FIGURE 1 Mean weekly binge episodes over 16 weeks of sodium oxybate treatment.

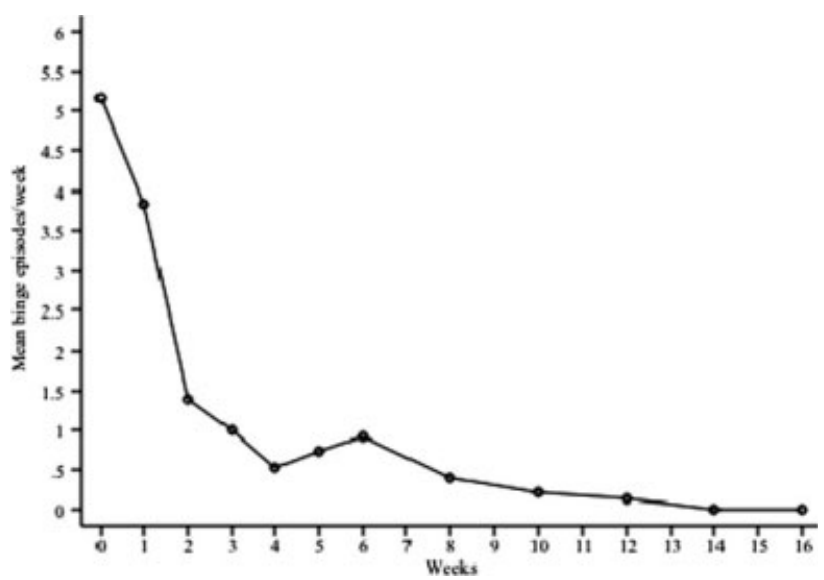

ated with a significant reduction in frequency of binges, frequency of binge days, weight, BMI, illness severity, obsessive-compulsive features of binge eating symptoms, eating pathology, and food craving. There was no significant increase in MADRS scores, which were low at baseline as required by protocol. These findings provide preliminary evidence for the effectiveness of sodium oxybate in binge eating disorder.

The potential mechanism of action of sodium oxybate in binge eating disorder is unknown. Sodium oxybate may decrease binge eating through

FIGURE 2 Cumulative mean weight (kg) loss over 16 weeks of sodium oxybate treatment.

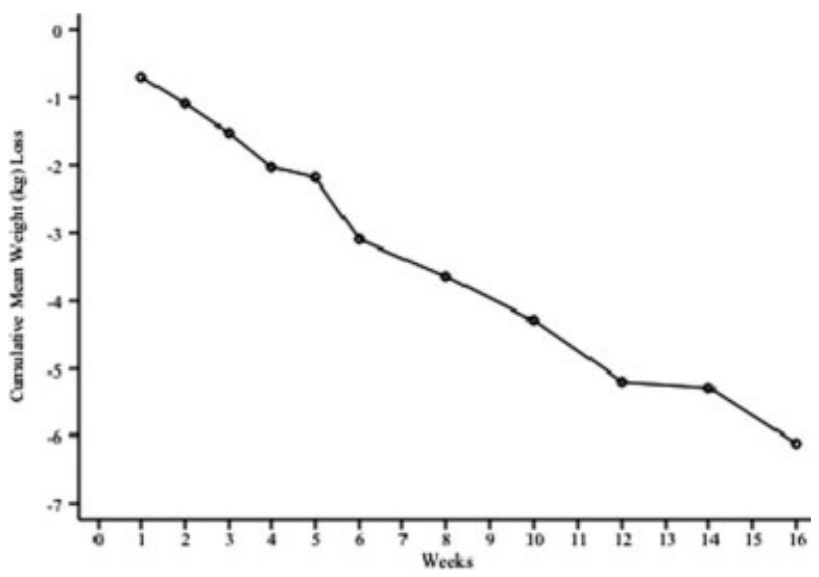


one or a combination of its mechanisms on neurotransmitter systems that affect feeding behavior. Thus, it increases serotonin turnover and interacts with the opioid, glutamate, and dopamine systems. ${ }^{17}$ It may also reduce binge eating by decreasing craving via acting as a GABA $B$ agonist. GABA $_{B}$ receptor antagonists have been shown to attenuate GHB-induced changes in operant responding, ${ }^{18}$ including food-maintained behavior in baboons. ${ }^{26}$ Weight loss may occur through a decrease in energy intake due to a reduction in binge eating.

Several limitations of this study should be considered. First, because the study was uncontrolled, the observed improvement could represent placebo response, rater bias, or participant bias. Indeed, binge eating in binge eating disorder has been associated with substantial response to placebo in many randomized, controlled trials. ${ }^{57}$ However, as the obesity associated with binge eating disorder generally does not responded to placebo, the significant weight loss seen in this trial suggests sodium oxybate may be associated with real therapeutic effects.

Second, the study group was small, all women, and many forms of psychiatric and medical pathology were excluded. In addition, the duration of treatment was short (16 weeks) and the discontinuation rate was high. Thus, the results may not generalize to larger, more diverse groups of persons with binge eating disorder or to longer treatment periods. Because of these limitations, together with sodium oxybate's abuse liability and risk for CNS depression, the use of sodium oxybate in binge eating disorder must be considered experimental at this time.

In summary, in an open-label, prospective, 16week, flexible-dose trial, sodium oxybate was found to be effective and relatively well tolerated in reducing binge frequency, weight, and severity of illness in individuals with binge eating disorder. Because of the study's limitations, these results should be considered highly preliminary and in need of replication in adequately sized placebocontrolled trials.

\section{References}

1. American Psychiatric Association. Diagnostic and Statistical Manual of Mental Disorders, 4th ed., Text Revision. Washington, DC: American Psychiatric Association, 2000.

2. Hudson JI, Hiripi E, Pope HG Jr, Kessler RC. The prevalence and correlates of eating disorders in the National Comorbidity Survey Replication. Biol Psychiatry 2007;61:348-358.
3. Pope HG Jr, Lalonde JK, Pindyck LJ, Walsh T, Bulik CM, Crow SJ, et al. Binge eating disorder: A stable syndrome. Am J Psychiatry 2006;163:2181-2183.

4. Striegel-Moore RH, Franko DL. Should binge eating disorder be included in the DSM-V? A critical review of the state of the evidence. Annu Rev Clin Psychol 2008;4:305-324.

5. Yager J. Binge eating disorder: The search for better treatments. Am J Psychiatry 2008;165:4-6.

6. Brownley KA, Berkman ND, Sedway JA, Lohr KN, Bulik CM. Binge eating disorder treatment: A systematic review of randomized controlled trials. Int J Eat Disord 2007;40:337-348.

7. Reas DL, Grilo CM. Review and meta-analysis of pharmacotherapy for binge-eating disorder. Obesity (Silver Spring) 2008;16: 2024-2038.

8. McElroy SL, Shapira NA, Arnold LM, Keck PE, Rosenthal NR, Wu SC, et al. Topiramate in the long-term treatment of binge-eating disorder associated with obesity. J Clin Psychiatry 2004; 65:1463-1469.

9. McElroy SL, Hudson JI, Capece JA, Beyers K, Fisher AC, Rosenthal NR. Topiramate for the treatment of binge eating disorder associated with obesity: A placebo-controlled study. Biol Psychiatry 2007;61:1039-1048.

10. McElroy SL, Kotwal R, Guerdjikova AI, Welge JA, Nelson EB, Lake $\mathrm{KA}$, et al. Zonisamide in the treatment of binge eating disorder with obesity: A randomized controlled trial. J Clin Psychiatry 2006;67:1897-1906.

11. McElroy SL, Guerdjikova A, Kotwal R, Welge JA, Nelson EB, Lake $K A$, et al. Atomoxetine in the treatment of binge-eating disorder: A randomized placebo-controlled trial. J Clin Psychiatry 2007;68:390-398.

12. Appolinario JC, Bacaltchuk J, Sichieri R, Claudino AM, GodoyMatos A, Morgan C, et al. A randomized, double-blind, placebocontrolled study of sibutramine in the treatment of binge-eating disorder. Arch Gen Psychiatry 2003;60:1109-1116.

13. Wilfley DE, Crow SJ, Hudson JI, Mitchell JE, Berkowitz RI, Blakesley $\mathrm{V}$, et al. Efficacy of sibutramine for the treatment of binge eating disorder: A randomized multicenter placebocontrolled double-blind study. Am J Psychiatry 2008;165:5158.

14. Padwal R, Kezouh A, Levine M, Etminan M. Long-term persistence with orlistat and sibutramine in a population-based cohort. Int J Obes (Lond) 2007;31:1567-1570.

15. McElroy SL, Guerdjikova A, O'Melia A. Pharmacotherapy of the eating disorders. In: Agras WS, editor. Oxford Handbook of Eating Disorders. Oxford University Press: USA

16. Lemon MD, Strain JD, Farver DK. Sodium oxybate for cataplexy. Ann Pharmacother 2006;40:433-440; quiz 581-432.

17. Pardi D, Black J. Gamma-hydroxybutyrate/sodium oxybate: Neurobiology, and impact on sleep and wakefulness. CNS Drugs 2006;20:993-1018.

18. Carter LP, Koek W, France CP. Behavioral analyses of GHB: Receptor mechanisms. Pharmacol Ther 2009;121:100-114.

19. Russell IJ, Perkins AT, Michalek JE. Sodium oxybate relieves pain and improves function in fibromyalgia syndrome: a randomized, double-blind, placebo-controlled, multicenter clinical trial. Arthritis Rheum 2009;60:299-309.

20. Scharf MB, Hauck M, Stover R, McDannold M, Berkowitz D. Effect of gamma-hydroxybutyrate on pain, fatigue, and the alpha sleep anomaly in patients with fibromyalgia. Preliminary report. J Rheumatol 1998;25:1986-1990.

21. Drasbek KR, Christensen J, Jensen K. Gamma-hydroxybutyrateA drug of abuse. Acta Neurol Scand 2006;114:145-156.

22. Carter LP, Pardi D, Gorsline J, Griffiths RR. Illicit gamma-hydroxybutyrate (GHB) and pharmaceutical sodium oxybate (Xyrem((R))): Differences in characteristics and misuse. Drug Alcohol Depend 2009;104:1-10. 
23. Zvosec DL, Smith SW, Hall BJ. Three deaths associated with use of Xyrem((R)). Sleep Med 2009;10:490-493.

24. Monograph XP. Available at: http://www.xyrem.com/.

25. Fuller DE, Hornfeldt CS, Kelloway JS, Stahl PJ, Anderson TF. The Xyrem risk management program. Drug Saf 2004;27:293-306.

26. Goodwin AK, Froestl W, Weerts EM. Involvement of gammahydroxybutyrate (GHB) and GABA-B receptors in the acute behavioral effects of GHB in baboons. Psychopharmacology (Berl) 2005;180:342-351.

27. Ottani A, Leone S, Vergara FB, Tacchi R, Loche A, Bertolini A. Preference for palatable food is reduced by the gamma-hydroxybutyrate analogue GET73, in rats. Pharmacol Res 2007;55: 271-279.

28. Husain AM, Ristanovic RK, Bogan RK. Weight loss in narcolepsy patients treated with sodium oxybate. Sleep Med 2008;10:661-663.

29. Dahmen N, Bierbrauer J, Kasten M. Increased prevalence of obesity in narcoleptic patients and relatives. Eur Arch Psychiatry Clin Neurosci 2001;251:85-89.

30. Schuld A, Beitinger PA, Dalal M, Geller F, Wetter TC, Albert ED, et al. Increased body mass index (BMI) in male narcoleptic patients, but not in HLA-DR2-positive healthy male volunteers. Sleep Med 2002;3:335-339.

31. Kok SW, Overeem S, Visscher TL, Lammers GJ, Seidell JC, Pijl H, et al. Hypocretin deficiency in narcoleptic humans is associated with abdominal obesity. Obes Res 2003;11:1147-1154.

32. Kotagal S, Krahn LE, Slocumb N. A putative link between childhood narcolepsy and obesity. Sleep Med 2004;5:147-150.

33. Chabas D, Foulon C, Gonzalez J, Nasr M, Lyon-Caen O, Willer JC, et al. Eating disorder and metabolism in narcoleptic patients. Sleep 2007;30:1267-1273.

34. Dahmen N, Becht J, Engel A, Thommes M, Tonn P. Prevalence of eating disorders and eating attacks in narcolepsy. Neuropsychiatr Dis Treat 2008;4:257-261.

35. Fortuyn HA, Swinkels S, Buitelaar J, Renier WO, Furer JW, Rijnders CA, et al. High prevalence of eating disorders in narcolepsy with cataplexy: A case-control study. Sleep 2008;31:335-341.

36. Gessa GL, Agabio R, Carai MA, Lobina C, Pani M, Reali R, et al. Mechanism of the antialcohol effect of gamma-hydroxybutyric acid. Alcohol 2000;20:271-276.

37. Caputo F, Addolorato G, Trevisani F, Bernardi M. Gamma-hydroxybutyrate as a treatment for alcoholism. Lancet 2005;366:981-982.

38. Caputo F, Addolorato G, Lorenzini F, Domenicali M, Greco G, del RA, et al. Gamma-hydroxybutyric acid versus naltrexone in maintaining alcohol abstinence: An open randomized comparative study. Drug Alcohol Depend 2003;70:85-91.

39. Beghe F, Carpanini MT. Safety and tolerability of gammahydroxybutyric acid in the treatment of alcohol-dependent patients. Alcohol 2000;20:223-225.

40. Poldrugo F, Addolorato G. The role of gamma-hydroxybutyric acid in the treatment of alcoholism: From animal to clinical studies. Alcohol 1999;34:15-24.

41. Avena NM, Rada P, Hoebel BG. Evidence for sugar addiction: Behavioral and neurochemical effects of intermittent, excessive sugar intake. Neurosci Biobehav Rev 2008;32:20-39.
42. Gold MS, Oppenheim HC, Frost-Pineda K. Obesity and substance use disorders. In: McElroy SL, Allison DB, Bray GA, editors. Obesity and Mental Disorders. New York: Taylor \& Francis, 2006.

43. O'Brien CP. Anticraving medications for relapse prevention: A possible new class of psychoactive medications. Am J Psychiatry 2005;162:1423-1431.

44. Marrazzi MA, Markham KM, Kinzie J, Luby ED. Binge eating disorder: Response to naltrexone. Int J Obes Relat Metab Disord 1995;19:143-145.

45. Broft AI, Spanos A, Corwin RL, Mayer L, Steinglass J, Devlin MJ, et al. Baclofen for binge eating: An open-label trial. Int J Eat Disord 2007;40:687-691.

46. First MB, Spitzer RL, Gibbon M, Williams JBW. Structured Clinical Interview for DSM-IV-TR Axis I Disorders. Research Version. Patient Edition (SCID-I/P). New York, NY: Biometrics, 2002.

47. Montgomery SA, Asberg M. A new depression scale designed to be sensitive to change. $\mathrm{Br}$ J Psychiatry 1979;134:382389

48. Netzer NC, Stoohs RA, Netzer CM, Clark K, Strohl KP. Using the Berlin Questionnaire to identify patients at risk for the sleep apnea syndrome. Ann Intern Med 1999;131:485-491.

49. First M, Spitzer R, Gibbon M, Williams JB. Structured Clinical Interview for DSM-IV-TR Axis I disorders, Research Version, Patient Edition (SCID-I/P). New York, NY: Biometrics Research Department, New York State Psychiatric Institute, 2002.

50. Fairburn CG, Beglin SJ. Assessment of eating disorders: Interview or self-report questionnaire? Int J Eat Disord 1994;16:363370

51. Guy W. ECDEU Assessment Manual for Psychopharmacology, U.S. Department of Health, Education, and Welfare publication (ADM). Rockville, MD: National Institute of Mental Health, 1976.

52. Goodman WK, Price LH, Rasmussen SA, Mazure C, Delgado P, Heninger GR, et al. The Yale-Brown Obsessive Compulsive Scale. II. Validity. Arch Gen Psychiatry 1989;46:1012-1016.

53. Stunkard A, Messick S. Eating Inventory Manual. San Antonio: The Psychological Corporation, Harcourt Brace \& Company, 1988.

54. White MA, Whisenhunt BL, Williamson DA, Greenway FL, Netemeyer RG. Development and validation of the food-craving inventory. Obes Res 2002;10:107-114.

55. McElroy SL, Kotwal R, Hudson JI, Nelson EB, Keck PE. Zonisamide in the treatment of binge-eating disorder: an open-label, prospective trial. J Clin Psychiatry 2004;65:50-56.

56. Brennan BP, Roberts JL, Fogarty KV, Reynolds KA, Jonas JM, Hudson JI. Memantine in the treatment of binge eating disorder: An open-label, prospective trial. Int J Eat Disord 2008;41:520526.

57. Jacobs-Pilipski MJ, Wilfley DE, Crow SJ, Walsh BT, Lilenfeld LR, West DS, et al. Placebo response in binge eating disorder. Int J Eat Disord 2007;40:204-211. 